\title{
Knockdown of HOXA10 reverses the multidrug resistance of human chronic mylogenous leukemia K562/ADM cells by downregulating P-gp and MRP-1
}

\author{
YING-JIE YI ${ }^{1 *}$, XIU-HONG JIA ${ }^{1 *}$, JIAN-YONG WANG ${ }^{2}$, YOU-JIE LI $^{3}$, HONG WANG ${ }^{1}$ and SHU-YANG XIE ${ }^{3}$ \\ ${ }^{1}$ Department of Pediatrics, The Affiliated Hospital of Binzhou Medical University, Binzhou, \\ Shandong 256603; ${ }^{2}$ Department of Pediatrics, Yantai Yuhuangding Hospital, Yantai, Shangdong 264000; \\ ${ }^{3}$ Department of Biochemistry and Molecular Biology, Key Laboratory of Tumour Molecular Biology, \\ Binzhou Medical University, Yantai, Shandong 264003, P.R. China
}

Received July 1, 2015; Accepted March 16, 2016

DOI: 10.3892/ijmm.2016.2539

\begin{abstract}
Multidrug resistance (MDR) of leukemia cells is a major obstacle in chemotherapeutic treatment. The high expression and constitutive activation of P-glycoprotein (P-gp) and multidrug resistance protein-1 (MRP-1) have been reported to play a vital role in enhancing cell resistance to anticancer drugs in many tumors. The present study aimed to investigate the reversal of MDR by silencing homeobox A10 (HOXA10) in adriamycin (ADR)-resistant human chronic myelogenous leukemia (CML) K562/ADM cells by modulating the expression of P-gp and MRP-1. K562/ADM cells were stably transfected with HOXA10-targeted short hairpin RNA (shRNA). The results of reverse transcription-quantitative polymerase chain reaction (RT-qPCR) and western blot analysis showed that the mRNA and protein expression of HOXA10 was markedly suppressed following transfection with a shRNA-containing vector. The sensitivity of the K562/ADM cells to ADR was enhanced by the silencing of HOXA10, due to the increased intracellular accumulation of ADR. The accumulation of ADR induced by the silencing of HOXA10 may be due to the downregulation of P-gp and MRP-1. Western blot analysis revealed that downregulating HOXA10 inhibited the protein expression of P-gp and MRP-1. Taken together, these results suggest that
\end{abstract}

Correspondence to: Dr Xiu-Hong Jia, Department of Pediatrics, The Affiliated Hospital of Binzhou Medical University, 661 Second Huanghe Road, Binzhou, Shandong 256603, P.R. China

E-mail: jiaxiuhong001@163.com

${ }^{*}$ Contributed equally

Abbreviations: GFP, green fluorescent protein; PBS, phosphatebuffered saline; SDS-PAGE, sodium dodecyl sulphate polyacrylamide gel electrophoresis; shRNA, short hairpin RNA; HOXA10 shRNA, homeobox A10 short hairpin RNA; control shRNA, control short hairpin RNA

Key words: multidrug resistance, homeobox A10, short hairpin RNA, reverse, P-glycoprotein, multidrug resistance protein-1 knockdown of HOXA10 combats resistance and that HOXA10 is a potential target for resistant human CML.

\section{Introduction}

Chronic myelogenous leukemia (CML) is one of the most common types of cancer in humans, and multidrug resistance (MDR) is a major factor that limits the efficacy of chemotherapeutic agents used to treat CML. MDR is a phenomenon characterized by the development of resistance in cancer cells to a variety of unrelated drugs following exposure to a single chemotherapy drug (1). MDR has many causes; however, the most widely studied mechanism involves the increased efflux of cytotoxic drugs, which is mediated by ATP-binding cassette (ABC) transporters (2). P-glycoprotein (P-gp) and multidrug resistance protein (MRP)-1 are members of the $\mathrm{ABC}$ transporter family, which are mainly expressed in the plasma membrane and pump the cytotoxic drugs out of the cells through active transportation. The increased expression of P-gp and MRP-1 has been demonstrated to cause reductions in the concentration of chemotherapeutic drugs inside tumor cells, thus reducing the clinical effectiveness of chemotherapy drugs (4-10). P-gp, the first member of the family to be identified, is a $170-\mathrm{kDa}$ energy-dependent drug efflux pump which mediates resistance to a variety of pharmacologically unrelated anticancer drugs, such as doxorubicin, epirubicin and paclitaxel (1-3). MRP-1, a drug-transporting MRP, is a $190-\mathrm{kDa}$ protein and is encoded by the MRP-1 gene, which is located on chromosome 16p13. MRP-1 overexpression has emerged as an important contributor to chemoresistance. In tumor cells, MRP-1 was found to cause resistance not only to doxorubicin, but also to many other chemotherapeutic drugs, including methotrexate, etoposide and vincristine (11).

Homeobox (HOX) proteins are homeodomain transcription factors that are highly conserved in many species, from Drosophila to humans. The human and murine HOX genes are found in four groups on four different chromosomes with 9-11 genes in each group (referred to as HOXA-D) (12-15). The HOX genes are important regulators encoding transcription factors that influence embryologic development. HOXA10 
belongs to the HOX gene family. HOXA10 is maximally expressed in the primitive hematopoietic cell compartment and decreases when the cells differentiate. In addition, it has been demonstrated that the overexpression of HOXA10 is involved in myelopoiesis and blocks differentiation, which may ultimately lead to myeloid leukemia $(13,16)$. Previous studies have confirmed that HOXA10 expression was associated with temozolomide resistance in glioblastoma (GBM) $(17,18)$. However, the role of HOXA10 in multidrug-resistant human CML K562/ADM cells was previously unknown. Thus, in the present study, we explored the effects of HOXA10 knockdown on multidrug resistance and the underlying molecular mechanism.

\section{Materials and methods}

Chemicals and reagents. Adriamycin (ADR; Melone Pharmaceutical Co., Ltd., Dalian, China) was dissolved at a concentration of $2 \mathrm{~g} / \mathrm{l}$ with $\mathrm{ddH}_{2} \mathrm{O}$ and divided into 25 aliquots. Rabbit polyclonal antibodies against HOXA10 (cat. no. bs-2502R), P-gp (cat. no. bs-0563R), MRP-1 (cat. no. bs-0657R) were obtained from Biosynthesis Biotechnology Co., Ltd. (Beijing, China). Rabbit polyclonal antibodies against GAPDH were obtained from Hangzhou Goodhere Biotechnology Co., Ltd. (Hangzhou, China).

Cell lines and cell culture. The human CML cell line, K562, was obtained from the Key Laboratory of Tumour Molecular Biology of Binzhou Medical University (Binzhou, China) and its MDR subline, K562/ADM, was obtained from the Department of Pharmacology at the Institute of Hematology of the Chinese Academy of Medical Sciences (Tianjin, China). The cells were cultured in RPMI-1640 medium supplemented with $10 \%$ fetal bovine serum (FBS) (both from HyClone Laboratories, Inc., Logan, UT, USA) at $37^{\circ} \mathrm{C}$ in a humidified atmosphere containing $5 \% \mathrm{CO}_{2}$. K562/ADM cells were maintained in the presence of $4 \mathrm{mg} / \mathrm{l} \mathrm{ADR}$. Prior to the experiment, the cells were cultured in drug-free medium for one week.

Determination of multidrug resistance in K562/ADM cells. A Cell Counting kit 8 (CCK8; Dojindo Molecular Technologies, Inc., Shanghai, China) was used to determine the survival rate of cells incubated with ADR at various concentrations (0.2-1.6 mg/l for the K562 cells and $16-128 \mathrm{mg} / \mathrm{l}$ for the K562/ADM cells), as previously described (7). After dilution in RPMI-1640 medium for $24 \mathrm{~h}, 10 \mu \mathrm{l}$ CCK8 solution was added to each well and incubated for 1-4 h. The absorbance was then measured at $570 \mathrm{~nm}$ with a fluorescence spectrofluorometer (F-7000; Hitachi High-Technologies Corp., Tokyo, Japan). A blank well containing only medium and ADR was used as a control. The concentration of ADR causing 50\% inhibition of cell growth $\left(\mathrm{IC}_{50}\right)$ was calculated (19).

Determination of gene expression by reverse transcription-quantitative polymerase chain reaction ( $R T-q P C R)$. Total RNA was isolated using TRIzol reagent (Invitrogen, Carlsbad, CA, USA), according to the manufacturer's instructions, followed by the synthesis of first strand cDNA using $2 \mu \mathrm{g}$ total RNA. The primers (Table I) used in this experiments were designed using Primer 5 version 5.6.0 software and synthesized by Sangon Biotech Co., Ltd. (Shanghai, China).
Table I. Primers used in reverse transcription-quantitative polymerase chain reaction.

\begin{tabular}{llc}
\hline Gene & \multicolumn{1}{c}{ Primer sequence } & $\begin{array}{c}\text { Product } \\
\text { length } \\
\text { (bp) }\end{array}$ \\
\hline HOXA10 & F: 5'-CTCACGGCAAAGAGTGGTC-3' & \\
& R:5'-AGTTTCATCCTGCGGTTCTG-3' & 182 \\
GAPDH & F: 5'-TGACTTCAACAGCGACACCCA-3' & \\
& R:5'-CACCCTGTTGCTGTAGCCAAA-3' & 121 \\
\hline
\end{tabular}

HOXA10, homeobox A10; F, forward; R, reverse.

Reverse transcription was performed with a PrimeScript ${ }^{\mathrm{TM}}$ RT reagent kit with gDNA Eraser (Takara Bio, Inc., Otsu, Japan). PCR amplification was performed on an Eppendorf Mastercycler personal (Eppendorf China Co., Ltd., Shanghai, China) using Premix Taq $^{\mathrm{TM}}$ (Takara Bio, Inc.). The reaction system contained diethyl pyrocarbonate, forward primer, reverse primer, Premix Taq and template cDNA. The amplification was as follows: $95^{\circ} \mathrm{C}$ for $2 \mathrm{~min}$, then 35 cycles of $95^{\circ} \mathrm{C}$ for $30 \mathrm{sec}, 60^{\circ} \mathrm{C}$ for $30 \mathrm{sec}, 72^{\circ} \mathrm{C}$ for $1 \mathrm{~min}$, followed by a full extension cycle of $72^{\circ} \mathrm{C}$ for $5 \mathrm{~min}$. The PCR products were electrophoresed on $1.5 \%$ agarose gels (Takara Biotechnology Co., Ltd., Dalian, China), and stained with ethidium bromide for $15 \mathrm{~min}$. The images were captured with a Tanon gel imaging system. The results are expressed for each sample as band intensity relative to that of GAPDH.

qPCR was performed on an ABI PRISM 7500 real-time PCR system (Applied Biosystems, Foster City, CA, USA) using a SYBR-Green reaction kit (Takara Bio, Inc.). The PCR reaction system consisted of SYBR-Green reagent, forward primer, reverse primer, template cDNA and nuclease-free distilled water. The PCR conditions were as follows: $95^{\circ} \mathrm{C}$ for $30 \mathrm{sec}$, followed by 45 cycles of $95^{\circ} \mathrm{C}$ for $5 \mathrm{sec}$ and $60^{\circ} \mathrm{C}$ for $30 \mathrm{sec}$. GAPDH was used as an internal control. qPCR for each gene of each cDNA sample was assayed in triplicate. The results were calculated using the $2^{-\Delta \Delta \mathrm{Ct}}$ method. The following equations were used: $\Delta \mathrm{Ct}=\mathrm{Ct}($ target gene $)-\mathrm{Ct}(\mathrm{GAPDH})$; $\Delta \Delta \mathrm{Ct}=\mathrm{Ct}$ [short hairpin RNA (shRNA) cells] - Ct(untreated control).

In vitro transfection with shRNA. The HOXA10-specific shRNA and the control shRNA were synthesized with recombinant plasmids containing the green fluorescent protein (GFP) vector, pGPH1, purchased from Shanghai GenePharma Co., Ltd., (Shanghai, China). The target sequence of HOXA10 shRNA was as follows: 5'-GCCAAAUUAUCCCACAACA-3'. Prior to transfection, the cells were cultured in RPMI-1640 medium free of serum and antibiotics. shRNA transfection (at a final concentration of $1 \mu \mathrm{g}$ in all experiments) was performed using Lipofectamine ${ }^{\mathrm{TM}} 2000$ transfection reagent (Invitrogen) according to the manufacturer's instructions. Briefly, shRNAs and lipofectamine $(2.5 \mu \mathrm{l})$ were diluted in RPMI-1640 separately and incubated for $5 \mathrm{~min}$ at room temperature. The diluted solutions were then mixed and incubated for $15 \mathrm{~min}$ at room temperature. The mixtures were then added to each well containing cells and medium. In addition, the cells treated with 
Table II. Determination of multidrug resistance according to the sensitivity of K562/ADM and K562 cells to ADR (means $\pm \mathrm{SD}$ of triplicate experiments).

\begin{tabular}{lccc}
\hline Treatment & $\begin{array}{c}\mathrm{K} 562 / \mathrm{ADM} \\
\mathrm{IC}_{50}(\mu \mathrm{g} / \mathrm{ml})\end{array}$ & $\begin{array}{c}\mathrm{K} 562 \\
\mathrm{IC}_{50}(\mu \mathrm{g} / \mathrm{ml})\end{array}$ & $\begin{array}{c}\text { Fold } \\
\text { resistance }\end{array}$ \\
\hline ADR & $43.6783 \pm 0.33096^{\mathrm{a}}$ & $1.3966 \pm 0.01526$ & 31.2747
\end{tabular}

${ }^{\text {ap }}<0.05$ vs. K562 cells. ADR, adriamycin.

only Lipofectamine were considered as the blank control. The cell culture plates were subsequently incubated for $6 \mathrm{~h}$ at $37^{\circ} \mathrm{C}$ in an incubator. Subsequently, RPMI-1640 medium containing $20 \%$ FBS was added and the cells were then incubated under the abovementioned conditions. Transfection efficiency was examined under a fluorescence microscope (Olympus DP71; Olympus, Tokyo, Japan). RT-qPCR and western blot analysis were performed to determine the inhibitory efficacy. G418 (500 ng/ml; Life Technologies, Carlsbad, CA, USA) was then added to the medium after $48 \mathrm{~h}$ transfection, and the cells were cultured for 1 month to permit selection. The cells successfully transfected with HOXA10 shRNA and control shRNA were named HOXA10 shRNA and control shRNA cells.

Assay of the reversal efficacy of HOXA10 knockdown. The K562/ADM cells as well as the cells transfected with HOXA10 shRNA and the control shRNA were seeded into 96-well plates in the presence of various concentrations of ADR $(0-128 \mu \mathrm{g} / \mathrm{ml})$ for $24 \mathrm{~h}$ at $37^{\circ} \mathrm{C}$ in $5 \% \mathrm{CO}_{2}$, and the quantity and percentages of viable cells were determined using the CCK8 assay. Each group consisted of five parallel wells. ADR $\mathrm{IC}_{50}$ was calculated using the untreated cells as a $100 \%$ viable control. The reversal fold (RF) values, as a measure of the potency of reversal, were obtained using the following formula: $\mathrm{RF}=\mathrm{IC}_{50}$ of $\mathrm{K} 562 /$ $\mathrm{ADM} / \mathrm{IC}_{50}$ of HOXA10 shRNA.

Enhancement of intracellular ADR accumulation. The intracellular accumulation of ADR was monitored using a standard procedure. The K562/ADM cells, and cells transfected with HOXA10 shRNA and control shRNA were incubated for $1 \mathrm{~h}$ at $37^{\circ} \mathrm{C}$ with ADR (3 mg/l). The cells were then harvested by centrifugation $\left(1,500 \mathrm{rpm}\right.$ for $5 \mathrm{~min}$ at $4^{\circ} \mathrm{C}$ ) and washed twice with ice-cold phosphate-buffered saline (PBS). The cell-associated mean fluorescence intensity (MFI) of ADR was detected by a flow cytometer (FACS FC500; Beckman Coulter, Brea, CA, USA) with excitation/emission wavelengths of $485 / 585 \mathrm{~nm}$.

Western blot analysis. The cells were harvested, a total of $100 \mu \mathrm{l}$ lysis buffer was added and the protein concentration of the lysate was determined using a bicinchoninic acid protein assay kit (Beyotime Biotechnology, Shanghai, China). The lysed samples $(50 \mu \mathrm{g})$ were separated by $6-12 \%$ sodium dodecyl sulfatepolyacrylamide gel electrophoresis (SDS-PAGE) (Beyotime Biotechnology) with a constant voltage of $80 \mathrm{~V}$ for $0.5 \mathrm{~h}$ which was then switched to $100 \mathrm{~V}$ for another $1.5 \mathrm{~h}$. The resolved proteins were electrophoretically transferred to polyvinylidine difluoride membranes (EMD Millipore, Bedford, MA, USA) and blocked with $5 \%$ skimmed milk for $2 \mathrm{~h}$. Subsequently,
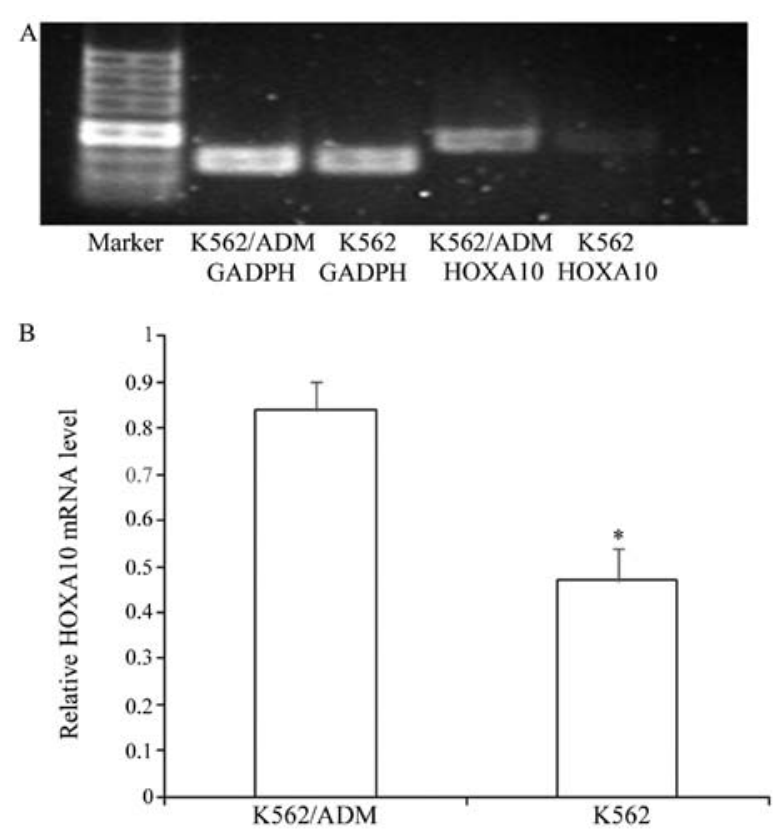

Figure 1. Expression of homeobox A10 (HOXA10) in K562/ADM cells and K562 cells. (A) RT-qPCR and (B) quantitative analysis showed that the expression of HOXA10 was higher in the K562/ADM cells than in the K562 cells. The average signal intensity was standardized to GAPDH, and the data are represented as the means $\pm \mathrm{SD}$ of triplicate experiments. ${ }^{*} \mathrm{P}<0.05$.

the membranes were incubated overnight at $4^{\circ} \mathrm{C}$ with specific antibodies. The primary antibodies used were rabbit polyclonal antibodies against HOXA10 (1:500), P-gp (1;500), MRP-1 $(1 ; 500)$ and GAPDH $(1 ; 1,000)$. The following day, the membranes were incubated in horseradish peroxidase-labeled goat anti-rabbit immunoglobulin G (1:5,000; cat. no. ZB-5301; Beijing Zhongshan Golden Bridge Biotechnology Co., Ltd., Beijing, China) for $2 \mathrm{~h}$ at room temperature. Finally, the images were captured using a FluorChem FC2 gel imaging system (Alpha Innotech, San Leandro, CA, USA). The intensity of each band was normalized to GAPDH for their respective lanes.

Data analysis. Statistical analyses were performed using SPSS 13.0 software (SPSS Inc., Chicago, IL, USA). Data are expressed as the means \pm SD. Statistical comparisons were evaluated by one-way ANOVA. A P-value $<0.05$ was considered to indicate a statistically significant difference.

\section{Results}

Comparison of multidrug resistance in K562/ADM cells and K562 cells. Compared with the non-resistant K562 cells, the K562/ADM cells exhibited significant resistance to ADR. As shown in Table II, a 31.2747-fold increase in resistance was observed in the K562/ADM cells in comparison with that in the non-resistant K562 cells $(\mathrm{P}<0.05)$ (Table II).

Expression of HOXA10 in K562 cells and K562/ADM cells. We determined the expression of HOXA10 in the non-resistant K562 cells and the resistant K562/ADM cells. We demonstrated that the K562 cells and K562/ADM cells exhibited high expression levels of HOXA10, while the K562/ADM cells expressed higher levels of HOXA10 than the K562 cells (Fig. 1) $(\mathrm{P}<0.05)$. 

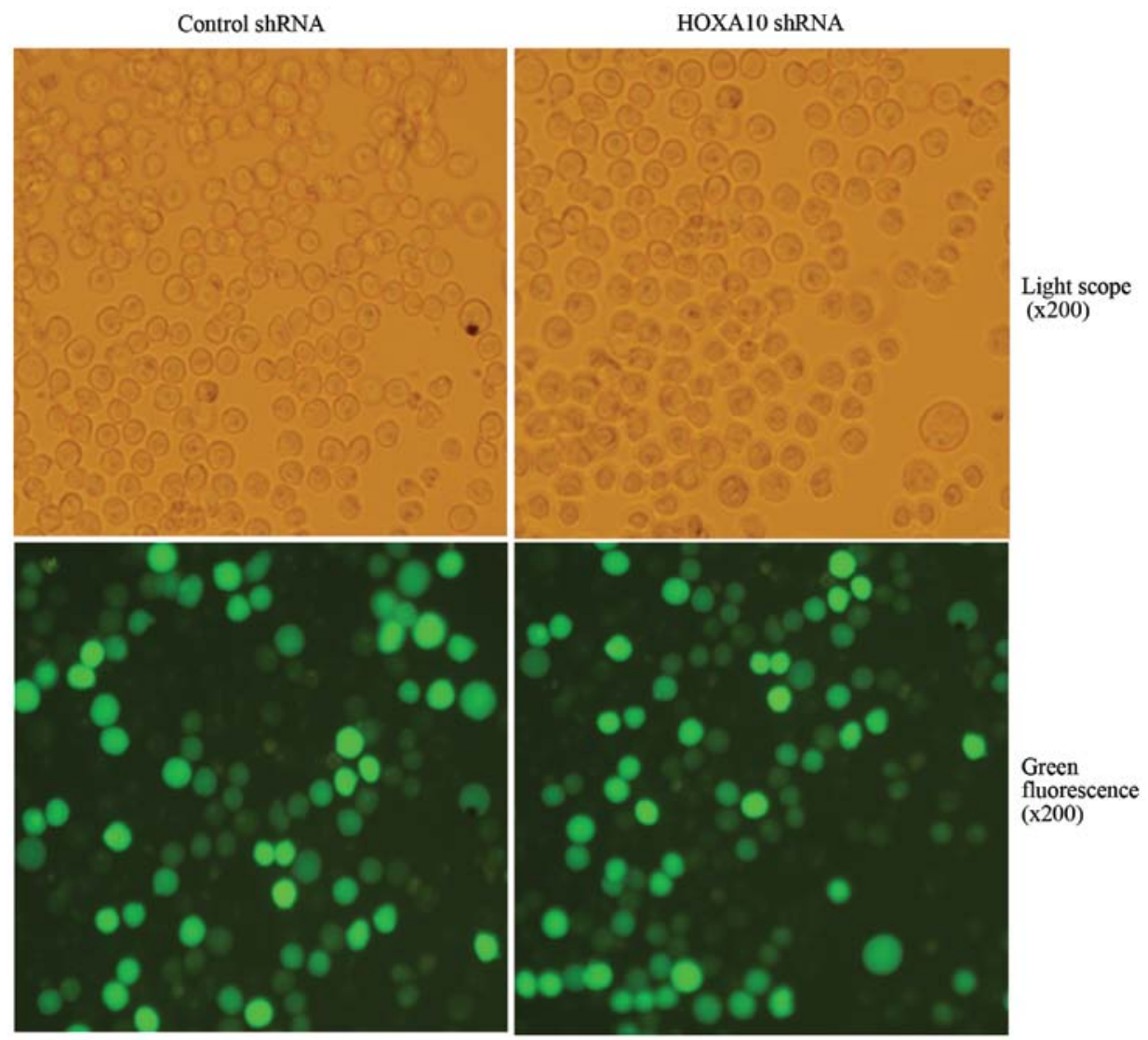

Figure 2. Transfection with homeobox A10 (HOXA10) targeting shRNA in K562/ADM cells. The transfection efficiency was detected by fluorescence microscopy. The average transfection efficiency of each group was $>80 \%$. Representative images are shown.

Suppression efficacy of HOXA10 shRNA. After transfection, more than $80 \%$ of cells were GFP-positive, indicating high transfection efficiency (Fig. 2). RT-qPCR analysis revealed that mRNA levels of HOXA10 in the K562/ADM cells transfected with HOXA10 shRNA decreased by $46.15 \pm 1.245 \%$, while the control shRNA had almost no influence on the HOXA10 mRNA levels in the K562/ADM cells $(\mathrm{P}<0.05)$ (Fig. 3A). Western blot analysis revealed that transfection with HOXA10 shRNA resulted in a reduction to $26.1 \pm 0.489 \%$ compared with that in the parental K562/ADM cells and the K562/ADM cells transfected with control shRNA $(\mathrm{P}<0.05)$ (Fig. 3B and $\mathrm{C})$.

Evaluation of ADR-induced cytotoxicity by knockdown of HOXA10. To determine whether the downregulation of HOXA10 affected multidrug resistance in vitro, the effect of HOXA10 shRNA on ADR-induced cytotoxicity was assessed by a CCK8 assay. The results are shown in Table III and Fig. 4. They indicated that after $24 \mathrm{~h}$, the K562/ADM cells transfected with HOXA10 shRNA had a slower rate of cell proliferation compared with the cells transfected with control shRNA and the parental K562/ADM cells ( $\mathrm{P}<0.05)$ (Fig. 4), suggesting that the transfection of HOXA10 shRNA increased ADR-induced cytotoxicity in the K562/ADM cells. Knockdown of HOXA10 caused a 2.587-fold reversal in the sensitivity of K562/ADM cells to ADR according to the results of a CCK8 assay $(\mathrm{P}<0.05)$ (Table III).

Knockdown of HOXA10 increases intracellular accumulation of $A D R$. It was previously noted that the intracellular accumulation of ADR decreased significantly in K562/ADM cells compared to the parental K562 cells (7). In the present study, we determined that knockdown of HOXA10 increased the intracellular accumulation of ADR in K562/ADM cells in comparison with K562/ADM cells transfected with control shRNA and parental K562/ADM cells. These results indicated that knockdown of HOXA10 increased the sensitivity of the K562/ADM cells to ADR through increasing the intracellular accumulation of ADR $(\mathrm{P}<0.05)$ (Fig. 5).

Knockdown of HOXA10 decreases the protein expression of $P$-gp and MRP-1 in K562/ADM cells. P-gp and MRP-1 are $\mathrm{ABC}$ transporters, which are overexpressed in many drugresistant cells $(9,11)$. In the present study, the K562/ADM cells expressed P-gp and MRP-1 at high levels. Western blot analysis revealed that after knockdown of HOXA10, P-gp and MRP-1 expression decreased markedly to $20.85 \pm 8.258 \%$ and $20.55 \pm 1.144 \%$, respectively (Fig. 6A-C). These results indicate that knockdown of HOXA10 decreases the protein expression of P-gp and MRP-1 by increasing the intracellular accumulation of ADR.

\section{Discussion}

We noted that silencing of HOXA10 significantly increased the cytotoxicity of ADR in K562/ADM cells. The effect of silencing HOXA10 is associated with the increased intracellular accumulation of ADR, as well as the inhibition of the expression of P-gp and MRP-1. 


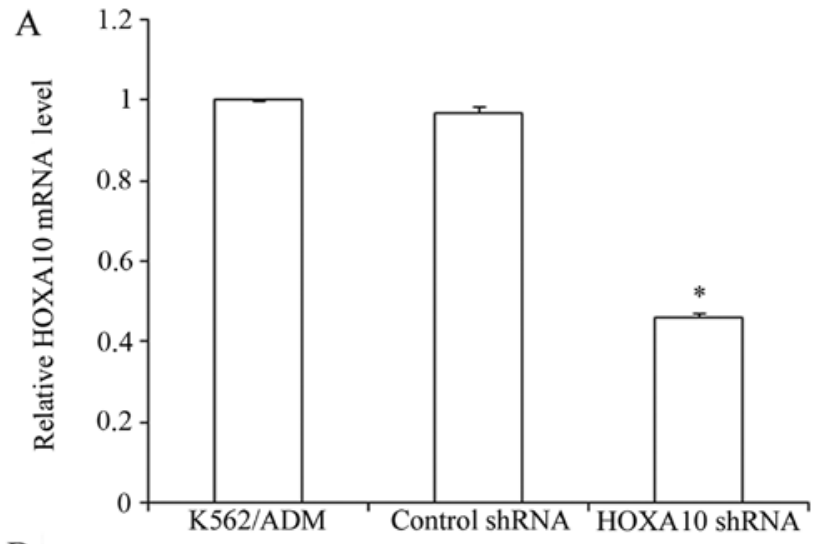

B

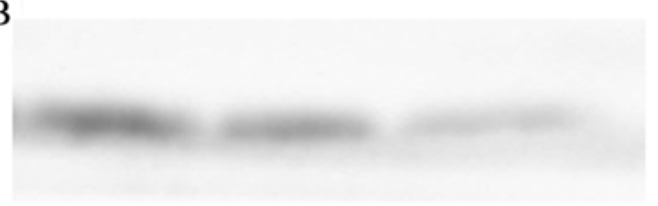

HOXA10
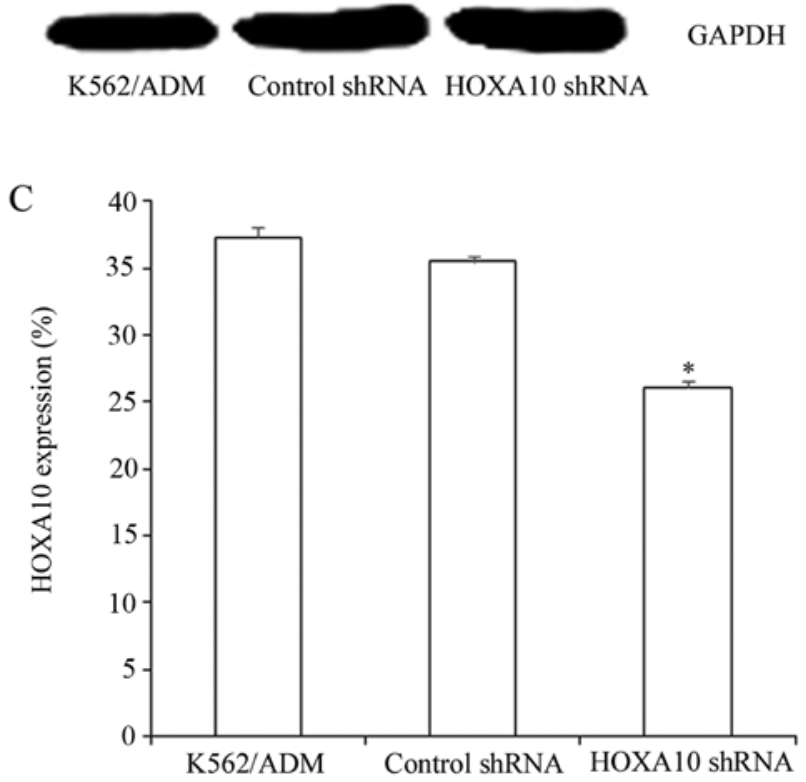

Figure 3. Effects of silencing homeobox A10 (HOXA10) on the mRNA and the protein expression of HOXA10 in K562/ADM cells. (A) The results of RT-qPCR showed that the mRNA expression of HOXA10 was significantly decreased by the HOXA10 shRNA vector compared with the control shRNA and the parental K562/ADM cells. (B and C) The protein expression of HOXA10 was measured by western blot analysis. The HOXA10 protein level was significantly suppressed by the HOXA10 shRNA vector compared with the control shRNA and the parental K562/ADM cells. The average signal intensity was standardized to GAPDH and the data are shown as the means \pm SD of triplicate experiments. ${ }^{*} \mathrm{P}<0.05$.

CML is a stem cell disorder characterized by chronic and blast-crisis phases (20). Chemotherapy plays a vital role in CML treatment; however, it is always accompanied by MDR which results in treatment failure. MDR in tumors is characterized by the ability of the tumor cells to exhibit simultaneous resistance to a number of structurally and functionally unrelated chemotherapeutic agents (21). There are multiple mechanisms of MDR in cancer, including the high expression of members of the $\mathrm{ABC}$ transporter family, and abnormalities in enzymatic systems and apoptosis. ADR is an effective chemotherapy

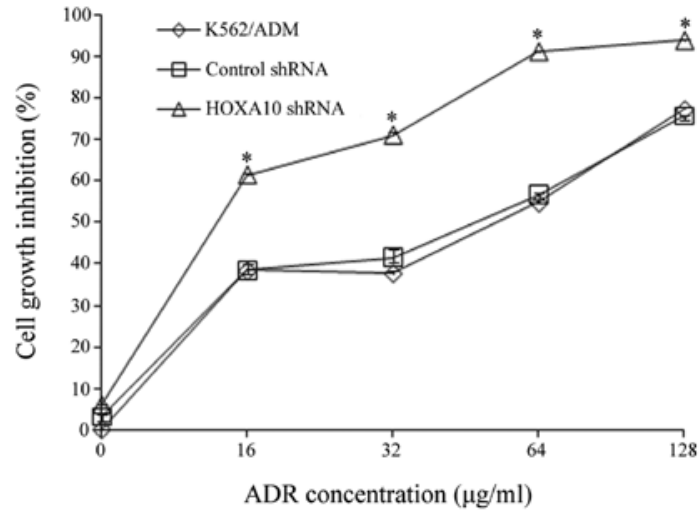

Figure 4. Effect of homeobox A10 (HOXA10) knockdown on adriamycin (ADR)-induced cytotoxicity. The cells were treated with different concentrations of ADR for $24 \mathrm{~h}$ prior to cell viability assessments. Data are expressed as the means \pm SD of triplicate experiments. ${ }^{*} \mathrm{P}<0.05$.

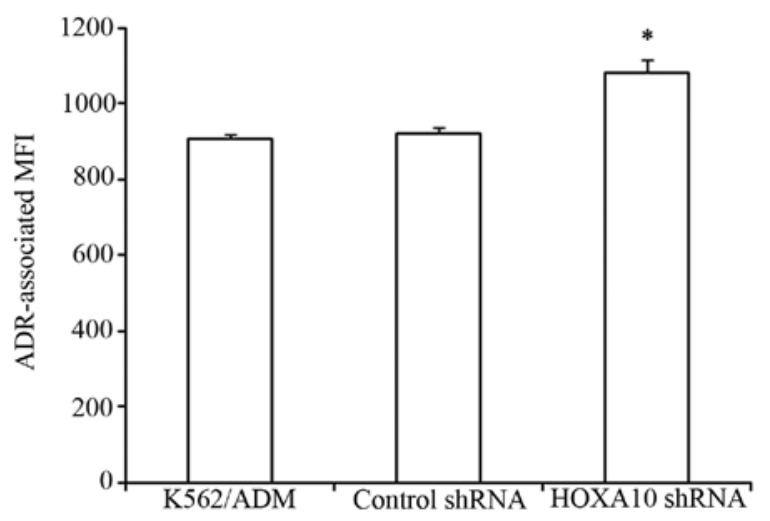

Figure 5. Knockdown of homeobox A10 (HOXA10) increased intracellular accumulation of adriamycin (ADR). The cells were treated with $3 \mu \mathrm{g} / \mathrm{ml}$ ADR for $1 \mathrm{~h}$. After removing the unbound ADR by washing, the cell-associated mean fluorescence intensity (MFI) of ADR was measured by flow cytometric analysis, with excitation/emission wavelengths of $485 / 585 \mathrm{~nm}$. Data are expressed as the means $\pm \mathrm{SD}$ of triplicate experiments. ${ }^{*} \mathrm{P}<0.05$.

Table III. Effect of silencing homeobox A10 (HOXA10) on the sensitivity of K562/ADM toward adriamycin (ADR) determined by CCK 8 assay (means \pm SD of triplicate experiments).

\begin{tabular}{lcc}
\hline Treatment & $\mathrm{IC}_{50}(\mu \mathrm{g} / \mathrm{ml})$ & Reversal fold \\
\hline ADR + K562/ADM & $44.4435 \pm 1.08027$ & \\
ADR + control shRNA & $42.1894 \pm 1.03356$ & 1.053 \\
ADR + HOXA10 shRNA & $17.1824 \pm 0.19211^{\mathrm{a}}$ & 2.587
\end{tabular}

${ }^{\mathrm{a}} \mathrm{P}<0.05$ vs ADR + K562/ADM and ADR + control shRNA groups.

drug that has been used extensively in the treatment of CML despite the emergence of MDR, which considerably limits the therapeutic efficacy of ADR (3). As shown in Table II, the K562/ADM cells demonstrated significant resistance to ADR-induced cytotoxicity. Overexpression of P-gp and MRP-1 is one of the best known causes of MDR. Significant efforts have been made to identify novel MDR-inhibiting genes, modulating the expression of P-gp and MRP-1. It has been 
A
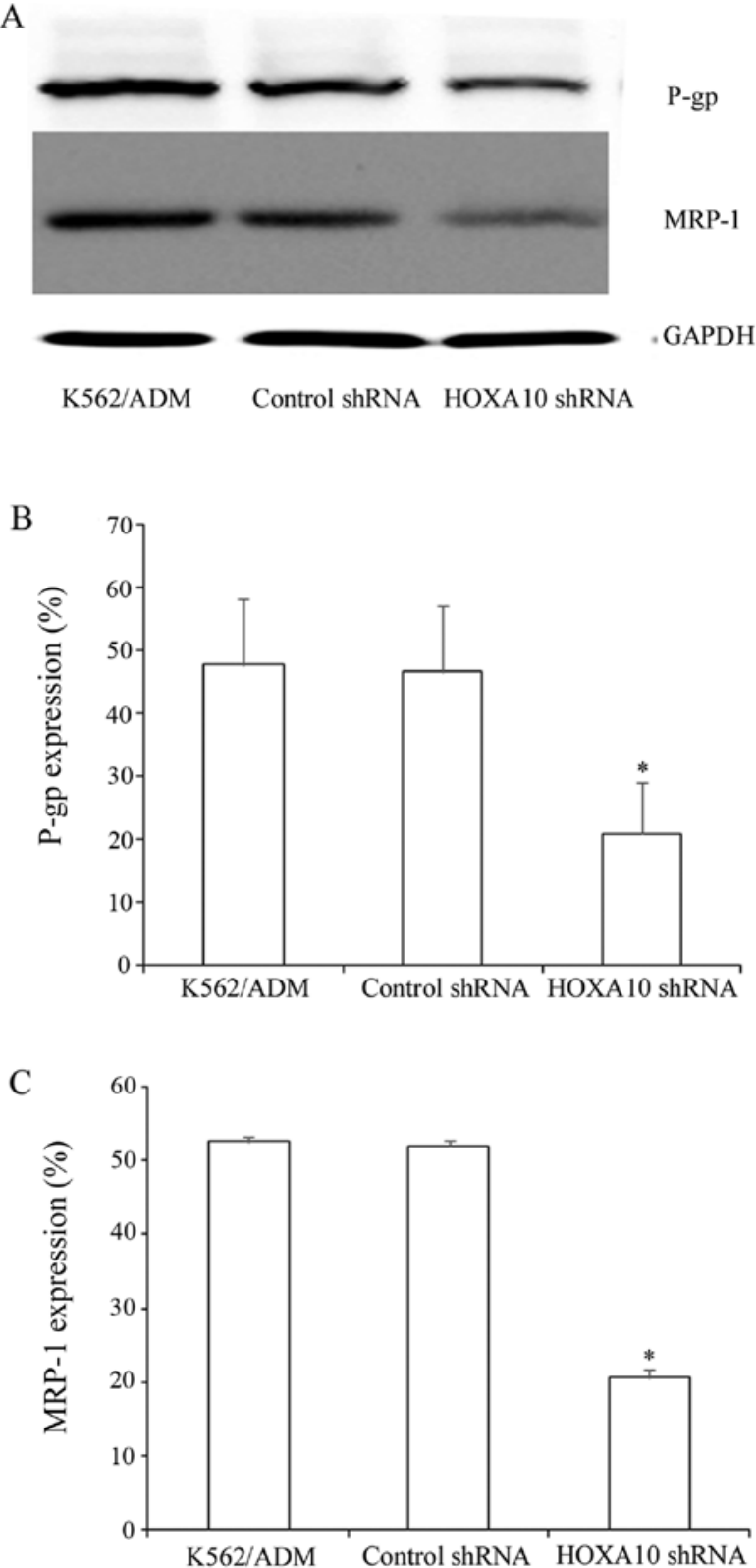

Figure 6. Knockdown of homeobox A10 (HOXA10) decreases the expression of P-glycoprotein (P-gp) and multidrug resistant protein-1 (MRP-1) in K562/ADM cells. (A) Protein expression levels, determined by western blot analysis. Expression levels of (B) P-gp and (C) MRP-1. Silencing HOXA10 inhibited the expression of P-gp and MRP-1. Data are expressed as the means $\pm \mathrm{SD}$ of triplicate experiments. ${ }^{*} \mathrm{P}<0.05$.

previously suggested that HOX genes are important regulators in normal and leukemic stem cells. HOXA10, a member of the HOX gene family, which has been reported to be an important regulator in normal and leukemic stem cells, is frequently overexpressed in myeloid leukemia (22-24). It has been reported that overexpression of HOXA10 may exert both pro-differentiation and anti-differentiation effects in a dose-dependent spatiotemporal manner (25). High levels of HOXA10 expression were predictive of tumor resistance to treatment. Studies have demonstrated that HOXA10 is associated with resistance in GBM $(17,18)$. The inhibition of HOXA10 reinforced temozolomide sensitivity independent of O6-methylguanine DNA methyltransferase (MGMT) status in GBM cell lines (17). High expression levels of the HOXA9/HOXA10 genes were noted in pediatric GBM patient samples as well as in a TMZ-resistant pediatric GBM cell line (18). Temozolomide resistance in the high HOXA9/HOXA10-expressing GBM cell line was independent of MGMT status, and the PI3K pathway was considered to be an upstream regulator of HOX genes that is targeted to overcome resistance (18). In the present study, we determined that the expression of HOXA10 was higher in the K562/ADM cell line than in the K562 cell line (Fig. 1).

The present study was designed to investigate the cellular functions of HOXA10 in order to elucidate the mechanism by which it contributes to reversing MDR of human CML-derived K562/ADM cell lines. The results revealed that the expression of HOXA10 was higher in the K562/ADM cells than in the K562 cell lines, which suggested that HOXA10 was involved in MDR of the K562/ADM cell lines. This study used shRNA to reduce the expression of HOXA10 in the human CML K562/ADM cell line. As shown in Fig. 3, the shRNA-containing vector efficiently suppressed HOXA10 expression at both the mRNA and protein levels. The effect of HOXA10 knockdown on the cellular functions of K562/ADM cells was then explored. The results of the CCK8 assay indicated that ADR-induced cytoxicity in the K562/ADM cells transfected with HOXA10 shRNA was significantly increased compared with that in the control cells, which confirmed that knockdown of HOXA10 was capable of reversing MDR in the K562/ADM cells (Fig. 4 and Table III). The flow cytometric analysis indicated that the silencing of HOXA10 increased the intracellular accumulation of ADR. These results indicated that knockdown of HOXA10 reversed MDR by increasing the intracellular accumulation of ADR. To further examine the mechanism by which knockdown of HOXA10 increased the intracellular accumulation of ADR within the K562/ADM cells, the expression of P-gp and MRP-1 were measured. Overexpression of P-gp and MRP-1, members of the ABC transporter family, lower intracellular drug accumulation and decrease the cellular toxicity of chemotherapeutic agents, such as adriamycin, daunorubicin, epirubicin, mitoxantrone, bisantrene, vincristine, vinblastine, etoposide and paclitaxel $(11,25)$. P-gp is one of the most well-known MDR-associated proteins, which functions as an ATP-dependent transmembrane drug transporter that reduces intracellular drug accumulation by pumping drugs out of cells (3). MRP-1, another energy-dependent drug pump, plays an important role in MDR by decreasing the intracellular accumulation of chemotherapeutics agents (5). In the present study, western blot analysis revealed that transfection with HOXA10 shRNA significantly decreased the expression of P-gp and MRP-1 compared with the expression levels in the cells transfected with control shRNA and the parental K562/ADM cells (Fig. 6). The decreased expression of P-gp and MRP-1 increased the intracellular accumulation of ADR in the K562/ ADM cells. Silencing of HOXA10 may increase the intracellular accumulation of ADR as a result of the downregulation of P-gp and MRP-1 proteins. Hence, the results confirmed that knockdown of HOXA10 reversed MDR through modulating the expression of P-gp and MRP-1.

In conclusion, HOXA10 was expressed at a high level in the K562/ADM cells, and knockdown of HOXA10 enhances the sensitivity of the K562/ADM cells to cytotoxic killing by the therapeutic drug, ADR, as a result of the increased intracellular accumulation of ADR. The accumulation of 
ADR induced by HOXA10 silencing was associated with the downregulation of P-gp and MRP-1 proteins. To the best of our knowledge, we are the first to suggest that knockdown of HOXA10 is a novel and potent therapeutic target that may be used for reversing MDR in human CML-derived mylogenous leukemia K562/ADM cells.

\section{Acknowledgements}

This study was supported by the Natural Science Foundation of Shandong Province (no. ZR2014HL032), the Projects of Medical and Health Technology Development Program in Shandong Province (no. 2014WS0183) and the Shandong Science and Technology Committee (no. 2010GSF10264).

\section{References}

1. Li H, Guo K, Wu C, Shu L, Guo S, Hou J, Zhao N, Wei L, Man X and Zhang L: Controlled and targeted drug delivery by a UV-responsive liposome for overcoming chemo-resistance in non-Hodgkin lymphoma. Chem Biol Drug 86: 783-794, 2015.

2. Nabekura T, Hiroi T, Kawasaki T and Uwai Y: Effects of natural nuclear factor-kappa B inhibitors on anticancer drug efflux transporter human P-glycoprotein. Biomed Pharmacother 70 140-145, 2015.

3. Ren J, Xu Y, Huang Q, Yang J, Yang M, Hu K and Wei K: Chabamide induces cell cycle arrest and apoptosis by the Akt/MAPK pathway and inhibition of P-glycoprotein in K562/ADR cells. Anticancer Drugs 26: 498-507, 2015.

4. Wen X, Zhang HD, Zhao L, Yao YF, Zhao JH and Tang JH: Ginsenoside Rh2 differentially mediates microRNA expression to prevent chemoresistance of breast cancer. Asian Pac J Cancer Prev 16: 1105-1109, 2015

5. Bao W, Zhu F, Duan Y, Yang Y and Cai H: HtrA1 resensitizes multidrug-resistant hepatocellular carcinoma cells by targeting XIAP. Biomed Pharmacother 70: 97-102, 2015.

6. Wang Z, Yang L, Xia Y, Guo C and Kong L: Icariin enhances cytotoxicity of doxorubicin in human multidrug-resistant osteosarcoma cells by inhibition of ABCB1 and down-regulation of the PI3K/Akt pathway. Biol Pharm Bull 38: 277-284, 2015.

7. Song YN, Guo XL, Zheng BB, Liu XY, Dong X, Yu LG and Cheng YN: Ligustrazine derivate DLJ14 reduces multidrug resistance of K562/A02 cells by modulating GST $\pi$ activity. Toxicol In Vitro 25: 937-943, 2011.

8. Ma J, Wang T, Guo R, Yang X, Yin J, Yu J, Xiang Q, Pan X, Tang $\mathrm{H}$ and Lei $\mathrm{X}$ : Involvement of miR-133a and miR-326 in ADM resistance of HepG2 through modulating expression of ABCC1. J Drug Target 23: 519-524, 2015.

9. Yang X, Iyer AK, Singh A, Choy E, Hornicek FJ, Amiji MM and Duan Z: MDR1 siRNA loaded hyaluronic acid-based CD44 targeted nanoparticle systems circumvent paclitaxel resistance in ovarian cancer. Sci Rep 5: 8509, 2015.

10. Fantappiè O, Sassoli C, Tani A, Nosi D, Marchetti S, Formigli L and Mazzanti R: Mitochondria of a human multidrug-resistant hepatocellular carcinoma cell line constitutively express inducible nitric oxide synthase in the inner membrane. J Cell Mol Med 19: 1410-1417, 2015.
11. Xu X, Zhang Y, Li W, Miao H, Zhang H, Zhou Y, Li Z, You Q, Zhao L and Guo Q: Wogonin reverses multi-drug resistance of human myelogenous leukemia K562/A02 cells via downregulation of MRP1 expression by inhibiting Nrf2/ARE signaling pathway. Biochem Pharmacol 92: 220-234, 2014

12. Bei L, Shah C, Wang H, Huang W, Roy R and Eklund EA: $\beta$-catenin activates the HOXA10 and CDX4 genes in myeloid progenitor cells. J Biol Chem 287: 39589-39601, 2012.

13. Wang H, Lindsey S, Konieczna I, Bei L, Horvath E, Huang W, Saberwal G and Eklund EA: Constitutively active SHP2 cooperates with HoxA10 overexpression to induce acute myeloid leukemia. J Biol Chem 284: 2549-2567, 2009.

14. Vitiello D, Pinard R and Taylor HS: Gene expression profiling reveals putative HOXA10 downstream targets in the periimplantation mouse uterus. Reprod Sci 15: 529-535, 2008.

15. Bei L, Huang W, Wang H, Shah C, Horvath E and Eklund E: Hox A10 activates CDX4 transcription and $\mathrm{Cdx} 4$ activates HOXA10 transcription in myeloid cells. J Biol Chem 286: 19047-19064, 2011.

16. Magnusson M, Brun AC, Miyake N, Larsson J, Ehinger M, Bjornsson JM, Wutz A, Sigvardsson M and Karlsson S: HOXA10 is a critical regulator for hematopoietic stem cells and erythroid/ megakaryocyte development. Blood 109: 3687-3696, 2007.

17. Kim JW, Kim JY, Kim JE, Kim SK, Chung HT and Park CK: HOXA10 is associated with temozolomide resistance through regulation of the homologous recombinant DNA repair pathway in glioblastoma cell lines. Genes Cancer 5: 165-174, 2014.

18. Gaspar N, Marshall L, Perryman L, Bax DA, Little SE, Viana-Pereira M, Sharp SY, Vassal G,Pearson AD, Reis RM, et al: MGMT-independent temozolomide resistance in pediatric glioblastoma cells associated with a PI3-kinase-mediated HOX/stem cell gene signature. Cancer Res 70: 9243-9252, 2010.

19. Wang JY, Jia XH, Xing HY, Li YJ, Fan WW, Li N and Xie SY: Inhibition of Forkhead box protein M1 by thiostrepton increases chemosensitivity to doxorubicin in T-cell acute lymphoblastic leukemia. Mol Med Rep 12: 1457-1464, 2015.

20. Sengupta A, Banerjee D, Chandra S, Banerji SK, Ghosh R, Roy R and Banerjee S: Deregulation and cross talk among Sonic hedgehog, Wnt, Hox and Notch signaling in chronic myeloid leukemia progression. Leukemia 21: 949-955, 2007.

21. Abdallah HM, Al-Abd AM, El-Dine RS and El-Halawany AM: P-glycoprotein inhibitors of natural origin as potential tumor chemo-sensitizers: a review. J Adv Res 6: 45-62, 2015.

22. Sloma I, Imren S, Beer PA, Zhao Y, Lecault V, Leung D, Raghuram K, Brimacombe C, Lambie K, Piret J, et al: Ex vivo expansion of normal and chronic myeloid leukemic stem cells without functional alteration using a NUP98HOXA10homeodomain fusion gene. Leukemia 27: 159-169, 2013.

23. Yao J, Fang LC, Yang ZL, Huang H, Li Y, Deng J and Zheng J: Mixed lineage leukaemia histone methylases 1 collaborate with $\mathrm{ER} \alpha$ to regulate HOXA10 expression in AML. Biosci Rep 34: e00156, 2014.

24. Zhang L, Wan Y, Jiang Y, Ma J, Liu J, Tang W, Wang X and Cheng W: Upregulation HOXA10 homeobox gene in endometrial cancer: role in cell cycle regulation. Med Oncol 31: 52, 2014.

25. Wang XB, Wang SS, Zhang QF, Liu M, Li HL, Liu Y, Wang JN, Zheng F, Guo LY and Xiang JZ: Inhibition of tetramethylpyrazine on P-gp, MRP2, MRP3 and MRP5 in multidrug resistant human hepatocellular carcinoma cells. Oncol Rep 23: 211-215, 2010. 